\title{
Prevention of Negative Impact of Pesticides and Other Toxic Substances on Reproductive Function of Animals
}

\author{
Salimov $\mathbf{Y}^{1 *}$ and Nurullaev $\mathrm{AA}^{2}$ \\ ${ }^{1}$ Department of veterinary surgery, pharmacology and toxicology, Uzbekistan \\ ${ }^{2}$ Department of biological science, Uzbekistan \\ *Corresponding author: Salimov Y, Department of veterinary surgery, pharmacology and toxicology, Uzbekistan
}

Received: 眥 January 04, 2019

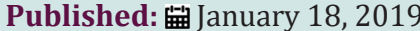

Keywords: Synthetic pyrethroid; Organophosphorus pesticides; Cypermethrin; Karate; Bazudin; Aktellik; Gossypol; Dimephosphone; Gamavit; Mexidol, MDU, mg/kg

\section{Introduction}

In acutely facing the problem of remote consequences of influence on an organism of chemical substances, impact on reproductive function is important. In recent years, in farms and private farms specializing in the cultivation of cattle and small cattle, as well as rabbits, there are violations of reproductive function, manifested in infertility and spontaneous abortions, pre - and postimplantation developmental delay, physiological and behavioral changes in the offspring, malformations and transplacental effects, and often their etiology remains unclear. Our long-term production and experimental studies allow us to conclude that one of the leading factors in the development of these violations is the unfavorable environmental situation in many regions of Uzbekistan as a result of various anthropogenic influences, including: the significant use of chemicals to protect plants and animals from pests and diseases, as well as other toxic substances. Currently, the most widespread as a means of protection of plants and animals from various pests have synthetic pyrethroids (cypermethrin, esfenvalerate, karate) and organophosphorus pesticides (basudin, aktellik, etapas, location) [1-3].

The use of these drugs helps to increase the yield of food and industrial crops, reduce production costs, protects productive animals from ecto - and endoparasites - carriers of various infections and invasions. However, their irrational use often causes environmental pollution (soil, water sources, feed) and causes poisoning, other negative consequences and, in particular, violations of the reproductive function of animals. Among other toxic substances that adversely affect the reproductive function of animals, gossypol cotton feed deserves some attention.

\section{Annotation}

Results on prevention of negative influence of pesticides and other toxic substances on reproductive function of animals are presented.

Some Signs of Reproductive Disorders Animals Under The Influence of Pesticides and Other Toxic Substances

Priority recognized violations of the reproductive function of animals manifested by a decrease in sexual activity, fertility, decreased ability to conceive and fertilization. Also take into account the severity of structural and functional disorders of gonads and sperm on the basis of the nature of changes in morphometric, biochemical and functional parameters of the state of gonads and sperm. We have established that the damaging effect of synthetic pyrethroids, organophosphorus pesticides and gossypol feed on the reproductive function of animals is realized by reducing fertility, abortion, increasing the number of stillbirths, pronounced weakness and high mortality of young people in the early period of postnatal development. At the same time, most organophosphorus drugs are characterized by a predominant effect on the generative ability of males. Gossypol distinguishes selective gonadotoxic effect 
on producers (bulls) of cattle and pronounced effect on sows, compared with boars $[4,5]$.

\section{Preventive Control}

Prevention of the negative impact of neo-somozan, atafona, tokuthion, Poltrona, aktellik, neocidol, esfenvalerate and gossypol on the reproductive function of farm animals is based on strict control over their content in various environmental objects. In this case, the maximum residue level (MRL) of these xenobiotics safe for the reproductive function are: Etats and tokution - 2,0; neocidol - 4.0 and neo-somozan, cypermethrin and esfenvalerate $-0.2 \mathrm{mg} / \mathrm{kg}$ of feed. The content of aktellik and gossypol in feed for reproductive groups of animals and birds is potentially dangerous and unacceptable. To prevent gospodarikov farm animals and poultry, long-term effects of this polyphenol is necessary to exercise strict control over its concentration in cottonseed meal and other feed, is scientifically proved to normalize their diet and include supplements Scamarcio bentonite in amounts of not less than $1.0 \mathrm{~g} /$ $\mathrm{kg}$ of animal weight. To control the content of these xenobiotics in the objects of veterinary supervision used chemical analytical detection methods based on thin-layer and gas chromatography.

Correction of violations of reproductive function of animals under the influence of chronic exposure to neo-tomozuna and
Sumi-alpha is a 3-fold, within 10 days of the use of dimephosphone $(250 \mathrm{mg} / \mathrm{kg})$ in combination with polyvinylpyrrolidone $(5.0 \mathrm{mg} / \mathrm{kg})$ parenteral (intramuscular) routes of administration. Other effective means of pharmacocorrection of violations of reproductive function of animals are preparations: "Gamavit", "Fosprenil"and "Mexidol". Treatment-and-prophylactic use in pregnant animals, chronic exposure esfenvalerate, immunomodulators T-type - "Gamavit" and "Fosprenil" ( V/m, weekly, throughout pregnancy, in doses of $0.1 \mathrm{ml} / \mathrm{kg}$, respectively), in combination with membraneprotective, antihypoxic drug "Mexidol" ( $\mathrm{V} / \mathrm{m}$ every ten days, at a dose of $10.0 \mathrm{mg} / \mathrm{kg}$ is a reliable protection of the reproductive function of animals and produce healthy young.

\section{References}

1. Zhulenko VN (2004) Veterinary toxicology. Kolos, Moscow, Russia, p. 384.

2. Medved LI (1974) Reference book on pesticides (hygiene applications and toxicology). Harvest, Kiev, Ukraine, p. 448.

3. John R (2008) Veterinary toxicology “Aquarium-Print”, p. 416.

4. Sanotsky IV (1970) Methods of determination of toxicity and danger of chemical substances. Medicine, Moscow, Russia, p. 232.

5. The headquarters of the method of determining the average lethal doses and concentrations of chemicals (1980) Hygiene and sanitation.

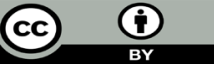

This work is licensed under Creative Commons Attribution 4.0 License

Submission Link: Submit Article

DOI: $10.32474 / C D V S .2019 .02 .000134$

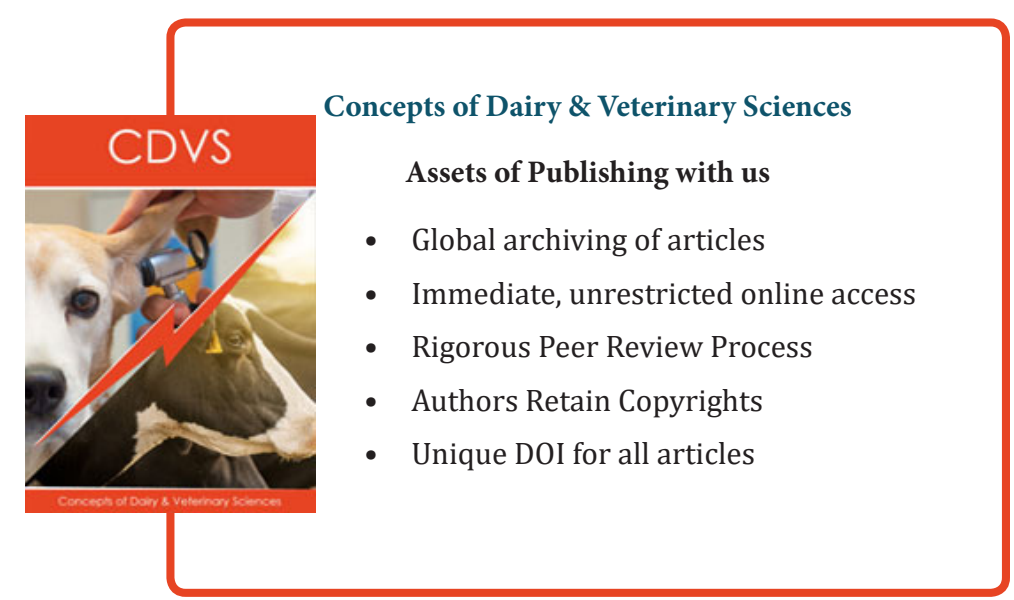

